\title{
CETVN - Centro de Estudos de Telenovela: Fale Conosco! A Gestão da Comunicação on-line
}

Ligia Maria Prezia Lemos

Redatora e roteirista pela Escola de Arte Dramática da Escola de Comunicações e Artes da Universidade de São Paulo e pela Faculdade de Belas Artes de São Paulo. É especialista em Gestão da Comunicação - Políticas, Educação e Cultura também pela ECA-USP. Bolsista do CNPq da equipe CETVN - Centro de Estudos de Telenovela/ECA-USP.

E-mail: ligia.lemos@terra.com.br

Resumo: Este trabalho apresenta um histórico do CETVN - Centro de Estudos de Telenovela da Escola de Comunicações e Artes da Universidade de São Paulo, desde sua criação até o período atual, passando por novembro de 2007, data em que seu site - nosso objeto de estudos - foi colocado no ar. Nossa pesquisa baseou-se na realização de entrevistas, análise comparativa com alguns sites, observação direta da relação do usuário com o site do CETVN, análise de conteúdo dos dados do sistema Fale Conosco e dos e-mails recebidos, pesquisa de opinião e uma rigorosa revisão bibliográfica. O projeto de intervenção proposto visa iniciar as discussões sobre a política, os objetivos e a atuação do site e implementar a sistematização de tarefas, a rotina de melhoria contínua do conteúdo e a gestão da comunicação com vistas à participação ativa do CETVN na rede de redes de computadores.

Palavras-chave: Comunicação on-line, telenovela, gestão da comunicação, CETVN, Internet.
Abstract: This study intends to display an historical overview of the CETVN - Centro de Estudos de Telenovela da Escola de Comunicações e Artes da Universidade de São Paulo (Telenovela Study Center of the University of São Paulo - Arts and Communication Program) since its beginning until current days. Remembering November 2007, when its website - our study object - was put on air. Our research was to conduct a set of interviews, comparative analysis of other websites, as well as the own CETVN website users. E-mails and contact formularies (Fale Conosco) were analyzed and considered in the study. We concluded with a opinion research and a complex bibliographic review. The project's goal is to start discussions about the website police, targets and interactivity tools, and from there keep improving its content, with a better communication process, aiming CETVN to an active participation at the world wide (wide) web.

Keywords: online communication, telenovela, communication management, CETVN, internet.

O CETVN - Centro de Estudos de Telenovela da Escola de Comunicações e Artes da Universidade de São Paulo ${ }^{1}$ foi criado em 8 de abril de 1992, com o objetivo de impulsionar a legitimação da telenovela como objeto de estudo

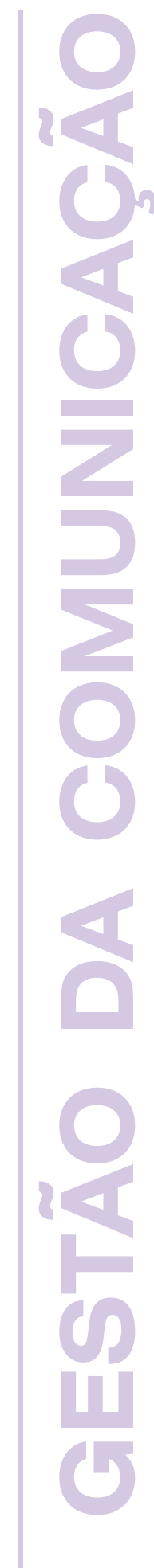

Recebido: 28.08.2010

Aprovado: 17.11 .2010

1. Adotaremos a sigla CETVN para nos referir ao Centro de Estudos de 
comunicação \& educação • Ano XVI • número 1 • jan/jun 2011

Telenovela da Escola de Comunicações e Artes ECA, da Universidade de São Paulo - USP.

2. DEL RÉ, Adriana. Núcleo de Telenovelas tenta voltar à atividade. Observatório da Imprensa. Disponível em: <http:// www.observatoriodaimprensa.com.br/artigos asp? cod =266ASP019> Acesso em: 16 ago. 2009 científico. Naquele momento, seu nome era NPTN - Núcleo de Pesquisa de Telenovela. O grande poder da telenovela no Brasil fez com que ela se transformasse em um objeto que se impôs imperativamente à pesquisa na Escola de Comunicações e Artes - ECA-USP. O CETVN surge, portanto, colocando a questão: qual a importância e o sentido de se estudar a telenovela brasileira? Como um fenômeno de massas pode intrigar cientistas e suscitar questionamentos, sejam eles acadêmicos ou não?

\section{HISTÓRIA}

Com o apoio de José Marques de Melo, Diretor da Escola de Comunicações e Artes da Universidade de São Paulo - ECA-USP, em 1992, Anamaria Fadul implanta o NPTN - Núcleo de Pesquisa de Telenovela, onde orienta trabalhos sobre o processo de produção de telenovela e ficção televisiva seriada, sendo sua coordenadora de 1992 a 1997. O núcleo torna-se referência nacional e internacional nas pesquisas acadêmicas sobre ficção televisiva desde os primeiros anos de sua criação. Em 1994, já se podia verificar o crescimento das pesquisas nacionais sobre telenovela e, a partir desta data, o núcleo passa a fazer parte do Departamento de Comunicações e Artes - CCA, da ECA-USP, contando com subsídios da FAPESP - Fundação de Amparo à Pesquisa do Estado de São Paulo.

De 1997 a 2000 assume a coordenação Maria Aparecida Baccega, responsável pela gestão do CCA e que já participava e liderava as pesquisas do Projeto Integrado: Ficção e Realidade: a telenovela no Brasil, o Brasil na telenovela, conhecido como Projetão. Este grupo, constituído no NPTN, intensificou as investigações sobre o tema de 1995 a 1998 e obteve reconhecimento e apoio financeiro de órgãos como a Pró-Reitoria de Cultura e Extensão da USP, FAPESP e CNPq.

A criação do núcleo de Ficção Televisiva na Intercom - Sociedade Brasileira de Estudos Interdisciplinares da Comunicação também foi um marco tanto do apoio à pesquisa, informação e memória da ficção televisiva seriada quanto do reconhecimento da telenovela como objeto de estudo científico.

De 2000 a 2005, Solange Martins Couceiro de Lima assume a coordenação, em liderança compartilhada, ao lado de Maria Lourdes Motter. Começam a surgir, então, outras iniciativas fundamentais para a construção do campo de estudo sobre telenovelas brasileiras e outras ficções televisivas seriadas, como minisséries, séries, seriados, soap operas e sitcoms.

Aos poucos estava sendo construído um novo objeto de estudo científico, mas, como se fosse num folhetim, em que o momento de harmonia dá lugar a uma tragédia inesperada, o enredo passa da comemoração de um trabalho bem realizado à comoção da destruição do acervo. Em dois de outubro de 2001, o NPTN, que se encontrava bem instalado no prédio central da Escola de Comunicações e Artes,

[...] com infraestrutura razoável, vasta documentação histórica, devidamente organizada, e status de referência para os estudos de telenovelas no Brasil e no exterior, sofre um incêndio em que tudo, absolutamente tudo, foi perdido, e os pesquisadores e professores do núcleo tiveram de recomeçar da estaca zero². 
Esse grande incêndio destruiu todo o acervo que:

[...] acomodava preciosidades, entre elas, 2.500 boletins do Ibope, 500 revistas nacionais, 300 revistas internacionais, 2.500 artigos, tirados de jornais, suplementos de tevê arquivados desde 1993, um dossiê de todas as telenovelas, datadas desde 1965 e separadas por pastas, 400 roteiros de novelas, 1.500 sinopses, 900 capítulos de novelas, sem contar fotografias, fitas de vídeo, pôsteres e discos ${ }^{3}$.

Após o desânimo inicial, os pesquisadores reagiram à perda do material com a campanha S.O.S. Telenovela - O que você guardou de lembrança pode ajudar nossa memória, com objetivo de dar continuidade ao trabalho; e, no dia 15 de maio de 2002, o NPTN, ao comemorar 10 anos de existência, inaugurava suas novas instalações.

A partir de 2005, assume a coordenação Maria Immacolata Vassallo de Lopes e começa a ser desenvolvido o projeto Obitel - Observatório Ibero-americano de Ficção Televisiva, um projeto internacional de pesquisa com o objetivo de "realizar a análise anual da produção, audiência e repercussão sociocultural da ficção televisiva na América Latina e Península Ibérica"4.

A rede de pesquisa Obitel Nacional, vinculada ao Obitel Internacional, é composta de pesquisadores distribuídos por universidades de todo o Brasil que, entre os países participantes do Obitel, possui a rede de pesquisadores mais expressiva devido ao vigor que a ficção televisiva exibe em nosso país. O CETVN e o Obitel firmaram e conservam parcerias com o Globo Universidade e o Ibope, fundamentais para o desenvolvimento de seu trabalho.

\section{O SITE DO CETVN}

A história do site do CETVN se inicia muito antes de seu lançamento. Começou a ser idealizado em 1998 pela pesquisadora Maria Ataíde Malcher, que contou com o auxílio de diversos voluntários dispostos a enfrentar essa empreitada, numa época em que poucas grandes empresas se arriscavam a

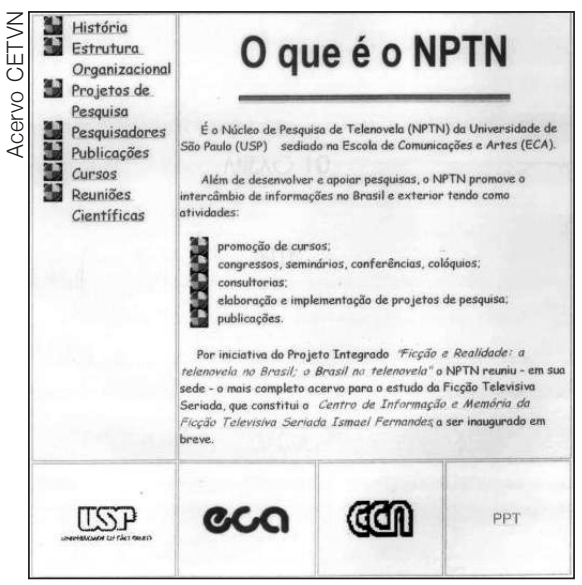

Projeto de Silvânia Soares e Maria Ataíde Malcher para o design da home do site do NPTN. tanto. O novo objeto de estudo científico, a telenovela, merecia maior visibilidade.

Durante os três anos que se seguiram, sem recursos, essa equipe idealizou o site, realizou o processo de organização do material, digitalizou arquivos, fez tratamento de imagens e levantamento de banco de dados e, finalmente, partiu para a busca por auxílio financeiro. Porém, como sabemos, em 2001, veio o incêndio e todo o acervo, equipamentos e arquivos se perderam. Com a proposta de disponibilizar parte significativa do acervo, "o que já era difícil acabou sendo abortado e o site como outros projetos foram abandonados".
3. Ibid.

4. LOPES, Maria Immacolata; VILCHES, Lorenzo (Org.). Anuário Obitel 2008: mercados globais, histórias nacionais. São Paulo: Globo, 2008. p. 11

5. Entrevista concedida à autora pela Profa $\mathrm{Dr}^{\mathrm{a}}$ Maria Ataíde Malcher, via e-mail, em 31 de outubro de 2009. 
Em 2007, o site foi retomado e criado um novo projeto para suas páginas. Foi desenvolvida, então, a estrutura que permanece até hoje. O design atual e o novo logotipo foram criados a partir da base de dados existente, com o qual se montou o sistema de busca de telenovelas, por décadas.

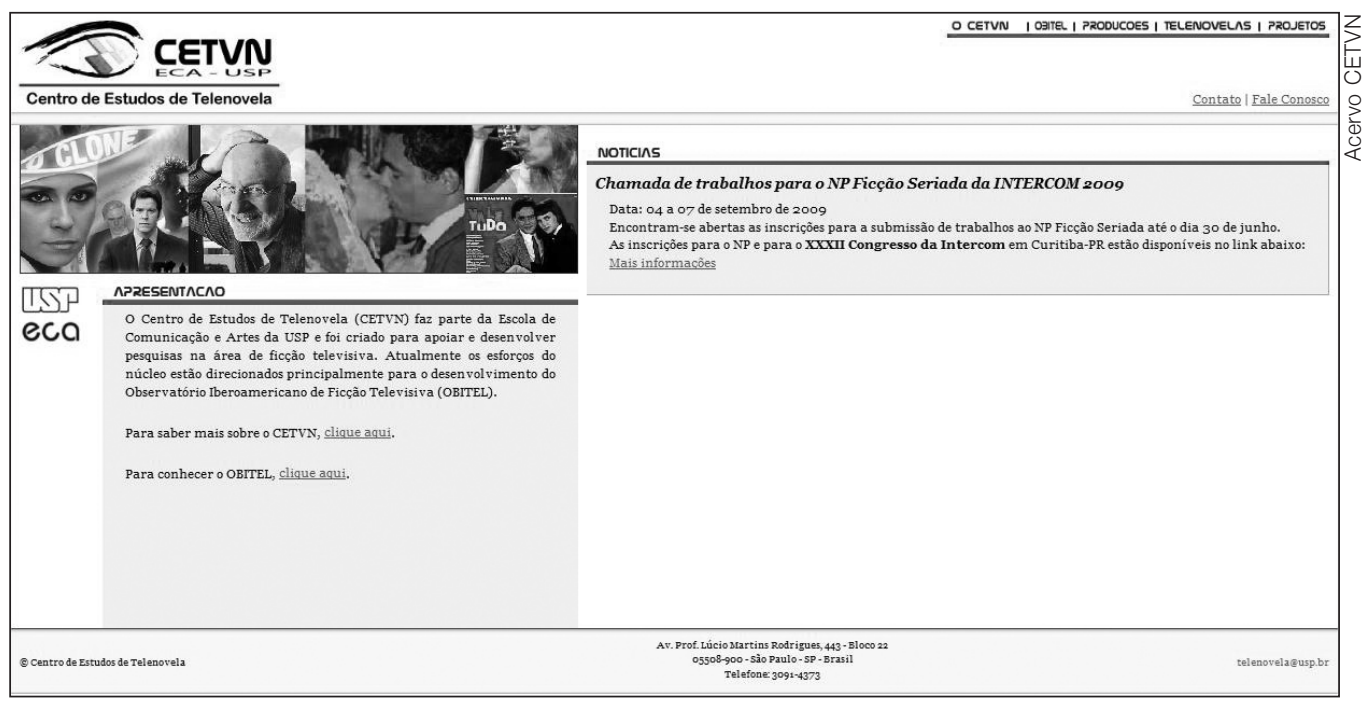

Site do CETVN, projeto de Marcelo Gomes. Disponível em: <http://www.eca.usp.br/cetvn/>.

O site do CETVN foi concebido de maneira a proporcionar informações sobre a história da telenovela e funciona como um grande resumo. Oferece uma ferramenta para encontrar as produções de determinado período, por emissora ou, no caminho inverso, obter a época de realização de determinada obra. A história da telenovela brasileira está organizada por décadas, de 1950 aos anos 2000. É um panorama desde o seu surgimento com exemplos significativos de cada momento. Também apresenta uma listagem com mais de trezentos artigos e livros sobre telenovela, em ordem alfabética ou por sistema de busca, distribuída por 19 páginas. O site traz o histórico, as atividades e apresenta o Núcleo de Pesquisa de Ficção Seriada da Intercom. Ainda oferece uma área de interação com o público, em Contato e com o Fale Conosco. A estatística do site é documentada e, nesses quase dois anos de funcionamento, registrou quatro mil visitantes e 80 contatos via Fale Conosco.

\section{PROJETO DE PESQUISA}

O nosso objetivo, neste trabalho, foi o de avaliar o site do CETVN do ponto de vista da Gestão da Comunicação, para saber se ele cumpre suas funções de estabelecer relações com o público acadêmico e com a sociedade em geral. Era nossa intenção, a partir dos resultados da pesquisa empírica, propor um Projeto de Intervenção que transformasse o site em ferramenta adequada ao processo de comunicação de um grupo de pesquisas da Universidade de São Paulo. Desenvolvendo a metodologia de trabalho, nossas ferramentas de pesquisa foram: 
análise comparativa do site do CETVN com outros sites de centros de pesquisa semelhantes; observação direta do site do CETVN; entrevistas; análise das mensagens recebidas pelo sistema Fale Conosco somadas aos e-mails diretamente enviados ao CETVN; e, finalmente, pesquisa de opinião com os usuários cadastrados pelo Fale Conosco somados aos que enviaram e-mails nos últimos seis meses.

Observamos nos sites de outros núcleos ou centros de estudos e pesquisas (Núcleo de Estudos da Violência - NEV, Centro de Estudos Rurais e Urbanos CERU, Núcleo de Estudos da Mulher - NEMGE, Arquivo Miroel Silveira - AMS e o do próprio Centro de Estudos de Telenovela - CETVN) apenas um fator especialmente relacionado a um dos pontos específicos de nosso interesse, ou seja, a proposta de comunicação on-line com o público usuário. Apesar de os cenários desses núcleos possuírem características distintas das do CETVN, tal análise nos possibilitaria recuperar os objetivos primeiros da construção do site do Centro: oferecer ao público acesso às informações sobre o acervo e pesquisas desenvolvidas. Verificamos que os endereços, os telefones e o e-mail para contatos estão presentes em todos os sites. Mas encontramos alguns diferenciais que nos oferecem pistas para aprimorar a relação com o público on-line, como, por exemplo, assessoria de imprensa, aviso do horário de funcionamento do centro ou núcleo e o sistema Fale Conosco.

Durante um período de observação do uso do site do CETVN, verificamos que a visitação e a interação revelam-se muito inferiores ao que inicialmente se esperaria. O que chama a atenção em primeiro lugar é o fato de um site sobre o estudo de telenovelas não apresentar vídeos nem links para vídeos sobre seu objeto. Em segundo lugar, notamos a falta de atualização do conteúdo do site. A informação atualizada do CETVN não está on-line, pois o site não foi concebido com este objetivo. Esta observação nos remete ainda a outra: o site foi idealizado linearmente, apresentando seu conteúdo tal como se fosse um texto impresso ou uma base biblioteconômica. Num momento em que até os livros buscam o hipertexto, esta constatação nos revela que o CETVN está na Internet, mas não está na Internet verdadeiramente - como sabemos, o "hipertexto é constituído de nós (os elementos de informação, parágrafos, páginas, imagens, sequências musicais etc.) e de links entre esses nós, referências, notas, ponteiros,

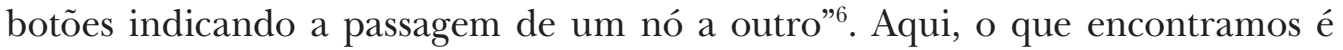
uma bandeira fincada, firme - mas o território ainda não foi ocupado. "Se a Internet constitui o grande oceano do novo planeta informacional, é preciso não esquecer os muitos rios que a alimentam."” Acreditamos que é o momento de questionar e propor uma concepção adequada a um centro de pesquisas de tão grande representatividade.

Nas entrevistas, utilizamos perguntas abertas. Foram realizadas seis entrevistas presenciais, uma por telefone e uma por e-mail com os profissionais que trabalham e com os que colaboraram com o CETVN.

O sistema Fale Conosco do site do CETVN permite que o Centro se relacione com o seu público, conheça quem se interessa por seu objeto de estudo, ofereça subsídios a quem necessita de auxílio e oriente quem busca parcerias. O Fale
6. LÉVY Pierre. As tecnologias da inteligência: o futuro do pensamento na era da informática. São Paulo: Editora 34, 2004. p. 56.

7. Ibid., p. 126. 
comunicação \& educação • Ano XVI • número 1 • jan/jun 2011

Conosco é um canal de visibilidade por onde a comunicação se inicia, por onde é possível verificar que a Internet atua como produtora de comunidades ligadas por um mesmo interesse:

Talvez o passo analítico necessário para se compreender as novas formas de interação social na era da Internet seja tomar por base uma redefinição de comunidade, dando menos ênfase a seu componente cultural, dando mais ênfase a seu papel de apoio a indivíduos e famílias, e desvinculando sua existência social de um tipo único de suporte material ${ }^{8}$.

Ao tabular os dados a partir do Fale Conosco, desde o seu lançamento em 2007 até outubro de 2009, somados aos e-mails diretamente enviados ao CETVN, no período de seis meses, obtivemos um total de 103 mensagens (Fale Conosco: 80; e-mail: 23). Realizamos uma tabulação por assunto para que pudéssemos perceber os anseios de nosso público on-line.

Realizamos a pesquisa de opinião com o mesmo universo de 103 pessoas. Utilizamos um formulário simples, com duas perguntas abertas e duas fechadas. Durante o período de 11 dias em que o formulário esteve aberto para acesso, obtivemos 33 respostas - equivalente a, apro-

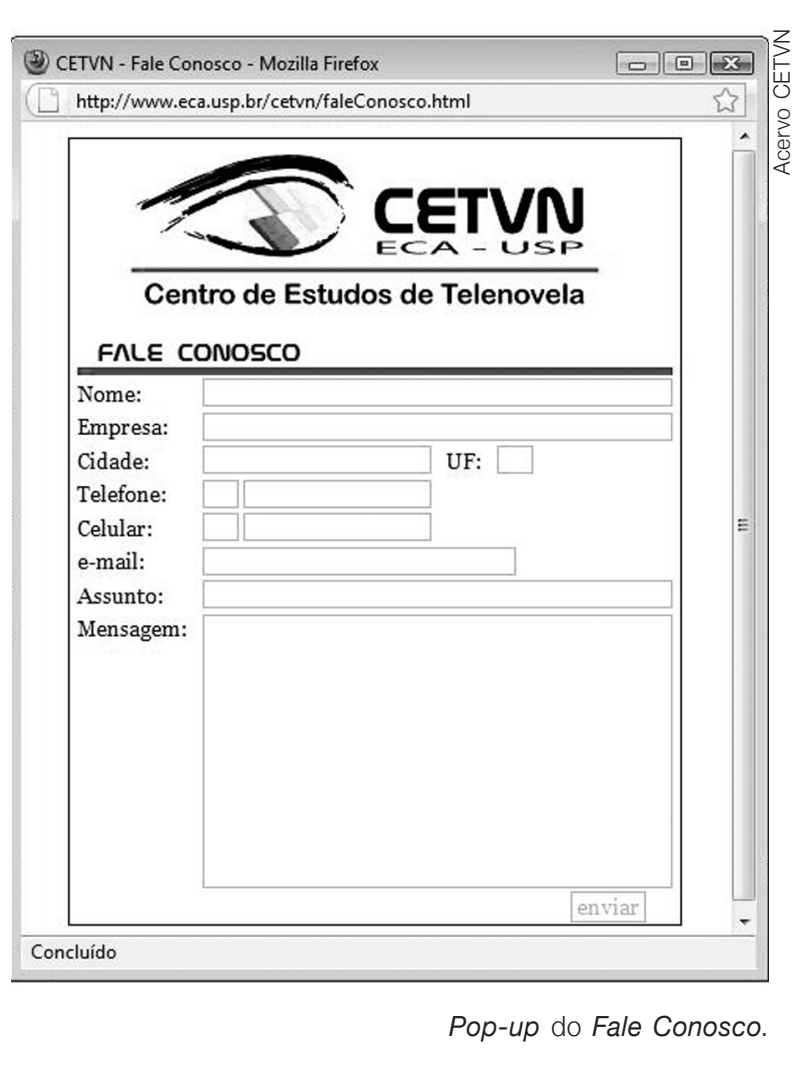

Pop-up do Fale Conosco.
8. CASTELLS, Manuel. A galáxia da internet: reflexões sobre a Internet os negócios e a sociedade. Rio de Janeiro: Jorge Zahar Editor, 2003a. p. 106.

9. BOURDIEU, Pierre. O campo científico. In: ORTIZ, Renato (Org.). Pierre Bourdieu: sociologia. São Paulo: Ática, 1983. p. 123. (Coleção Grandes Cientistas Sociais). ximadamente, $32 \%$ do universo.

\section{O PROJETO DE INTERVENÇÃO}

Repetimos Bourdieu para salientar que, hoje, garantir o espaço de credibilidade na rede é condição de consolidação da autoridade científica por meio da capacidade técnica e poder social ${ }^{9}$. A telenovela e a ficção seriada fazem parte de um mundo que está integrado à Internet e, ainda, que possui suas próprias narrativas ficcionais construídas a partir da rede. Os produtores de ficção televisiva, o público de televisão, o usuário de celular, o criador de um blog, os retransmissores de programação, os jornais, as revistas, os twitteiros, as comunidades do Orkut, os fãs do Facebook, os programas de celebridades, os professores de comunicação e os centros de estudos acadêmicos, com suas teses e dissertações, estão todos juntos nesse ecossistema dinâmico e disseminador 
de informações. Por essa razão é preciso pensar o estar na rede em relação e não apenas estaticamente. Segundo Castells,

[...] os componentes da rede tanto são autônomos quanto dependentes em relação à rede e podem ser uma parte de outras redes e, portanto, de outros sistemas de meios destinados a outros objetivos. Então, o desempenho de uma determinada rede dependerá de dois de seus atributos fundamentais: conectividade, ou seja, a capacidade estrutural de facilitar a comunicação sem ruídos entre seus componentes; e coerência, isto é, na medida em que há interesses compartilhados entre os objetivos da rede e de seus componentes ${ }^{10}$.

Pensando na capacidade de uma palpável conexão com o usuário do CETVN e na coerência deste contato, nosso projeto de intervenção para o site propõe dois níveis de abordagem: o primeiro - macro - visa a uma operação profunda e conceitual, de execução a médio e longo prazo; o segundo nível micro - investe em soluções menores, emergenciais e de curto prazo.

\section{MACROINTERVENÇÃO}

Tendo em vista as entrevistas realizadas, nossa observação direta e a análise e interpretação das comunicações enviadas pelo sistema Fale Conosco e e-mails diretos, desenvolvemos as propostas abaixo para o site do CETVN.

Realização de seminário para exposição de projeto de pesquisa, a fim de, a partir de então, extrair uma política de atuação para o site e o levantamento de novas premissas: a quem o site se destina, quais são suas prioridades e quais são as funcionalidades necessárias para sua atuação. Propomos inicialmente as seguintes alterações: nova concepção em termos de navegação, design e conteúdo, digitalização e disponibilização do acervo atualmente em papel e meio audiovisual, catalogação e exibição de vídeos de e sobre telenovela e ficção seriada, links para sites especializados, promoção de pesquisas tendo a Internet como veículo, gerenciamento de blog, publicação de clipping eletrônico e renovação da sistematização do conteúdo histórico e institucional.

Os padrões da Internet requerem serviços especializados e que demandam um capital destinado especialmente para esse fim. Portanto, este projeto de macrointervenção pretende buscar recursos financeiros nas agências de fomento para sua efetiva implantação.

\section{MICROINTERVENÇÃO}

A partir da análise comparativa e dos dados levantados e sistematizados em nossa pesquisa de opinião com os usuários do site do CETVN, propomos algumas intervenções pontuais, a serem executadas em caráter emergencial, com os recursos humanos e financeiros disponíveis, com o objetivo de melhorar a funcionalidade do site:
10. CASTELLS, Manuel. A sociedade em rede. São Paulo: Paz e Terra, 2003b. p. 232. (A era da informação: economia, sociedade e cultura, v. 1). 
comunicação \& educação • Ano XVI • número 1 • jan/jun 2011

1. Home: indicação de horário de funcionamento do CETVN; formas de acesso ao acervo: capítulos, livros e revistas; pesquisas em andamento e abertura de concorrência para Bolsas.

2. FAQ - Frequently Asked Questions: com informações sobre visitas, cursos, projetos e funcionamento.

3. Correções: corrigir links quebrados em Produções: artigos/livros a partir de pesquisa do link correto de cada indicação.

4. Atitude: resposta imediata aos contatos realizados pelo usuário. Criação de uma resposta padrão a ser enviada em caso de dias ou semanas em que a resposta demandaria atraso nas atividades diárias do CETVN.

5. Atualização: atividade integrante de parte da rotina.

\section{CONSIDERAÇÕES FINAIS}

O site do CETVN é parte importante de uma história de lutas e vitórias. E está inserido em uma realidade em que a troca simbólica e o domínio sobre a linguagem complexa são as moedas mais valiosas. Por meio deste trabalho pudemos observar que suas principais deficiências decorrem do fato de o ambiente da rede não ser considerado parte da filosofia e da política de trabalho do CETVN e, consequentemente, da rotina diária e do hábito cotidiano. Daí, propusemos um projeto de intervenção com sugestões de longo e curto prazo.

Aqui e agora, indicamos a criação e o desenrolar de uma nova história para o site do CETVN: uma trama que contenha, por um lado, racionalidade, aplicação dos estudos acadêmicos, visão dos meios de comunicação, emoção (porque está no âmago da telenovela!), recursos técnicos e tecnológicos e, por outro lado, a interdisciplinaridade, ou seja, a confluência da pesquisa de diversas áreas, pois "conhecer o humano, não é subtraí-lo ao Universo, mas sim aí situá-lo" 11 .

\section{REFERÊNCIAS BIBLIOGRÁFICAS}

BOURDIEU, Pierre. O campo científico. In: ORTIZ, Renato (Org.). Pierre Bourdieu: sociologia. São Paulo: Ática, 1983. (Coleção Grandes Cientistas Sociais).

CASTELLS, Manuel. A galáxia da Internet: reflexões sobre a Internet, os negócios e a sociedade. Rio de Janeiro: Jorge Zahar Editor, $2003 \mathrm{a}$.

. A sociedade em rede. São Paulo: Paz e Terra, 2003b. (A era da informação: economia, sociedade e cultura, v. 1).

COSTA, Maria Cristina Castilho. As formas narrativas em mídias eletrônicas.

11. MORIN, Edgar. Repensar a reforma, reformar o pensamento: a cabeça bem-feita. Lisboa: Instituto Piaget, s/d., p. 39 Relatório científico, São Paulo, ago. 2002.

LÉVY, Pierre. As tecnologias da inteligência: o futuro do pensamento na era da informática. São Paulo: Editora 34, 2004. 
LOPES, Maria Immacolata; VILCHES, Lorenzo (Org.). Anuário Obitel 2008: mercados globais, histórias nacionais. São Paulo, Globo, 2008.

MALCHER, Maria Ataíde. A memória da telenovela: legitimação e gerenciamento. São Paulo: Alexa Cultural, 2003.

MORIN, Edgar. Repensar a reforma, reformar o pensamento: a cabeça bem-feita. Lisboa: Instituto Piaget, s/d.

NICOLESCU, Basarab. O manifesto da transdisciplinaridade. São Paulo: Triom, 1999.

\section{Endereços eletrônicos}

DEL RÉ, Adriana. Núcleo de Telenovelas tenta voltar à atividade. Observatório da Imprensa. Disponível em: <http://www.observatoriodaimprensa.com.br/artigos. asp?cod=266ASP019>. Acesso em: 16 ago. 2009.

BRASIL mostra a sua cara na TV: pesquisas mostram que novelas ajudam a compreender o país. Revista Pesquisa Fapesp, edição impressa 54, jun. 2000. Disponível em: <http://revistapesquisa.fapesp.br/?art=980\&bd=1\&pg=1\&lg>. Acesso em: 29 ago. 2009.

PROJETO OBITEL e ficção televisiva no espaço ibero-americano. ECO-PÓS, v. 10, n. 2, p. 280-291, jul./dez. 2007. Disponível em: <http://www.pos.eco.ufrj.br/ ojs-2.2.2/index. php/revista/article/viewFile/98/77>. Acesso em: 26 set. 2009. 


\section{Do banco escolar para toda uma vida}

\section{As mudanças no ensino e na escola não se limitam à melhoria na aprendizagem do aluno, mas têm a dimensão ética, voltada para a transformação pessoal e social.}

uito se discute sobre a necessidade de se mudarem as práticas de ensino no Brasil de forma que favoreçam a apropriação de ferramentas teóricas e metodológicas úteis na vida profissional e pessoal, superando os baixos índices de aproveitamento que comprometem a inclusão do aluno na sociedade adulta. Entretanto, as mudanças mais difíceis dizem respeito à transformação das práticas características das relações sociopedagógicas tradicionais: dominação/subordinação, competitividade e individualismo.

Grupo de especialistas vinculado ao CNPq (Conselho Nacional de Desenvolvimento Científico e Tecnológi-

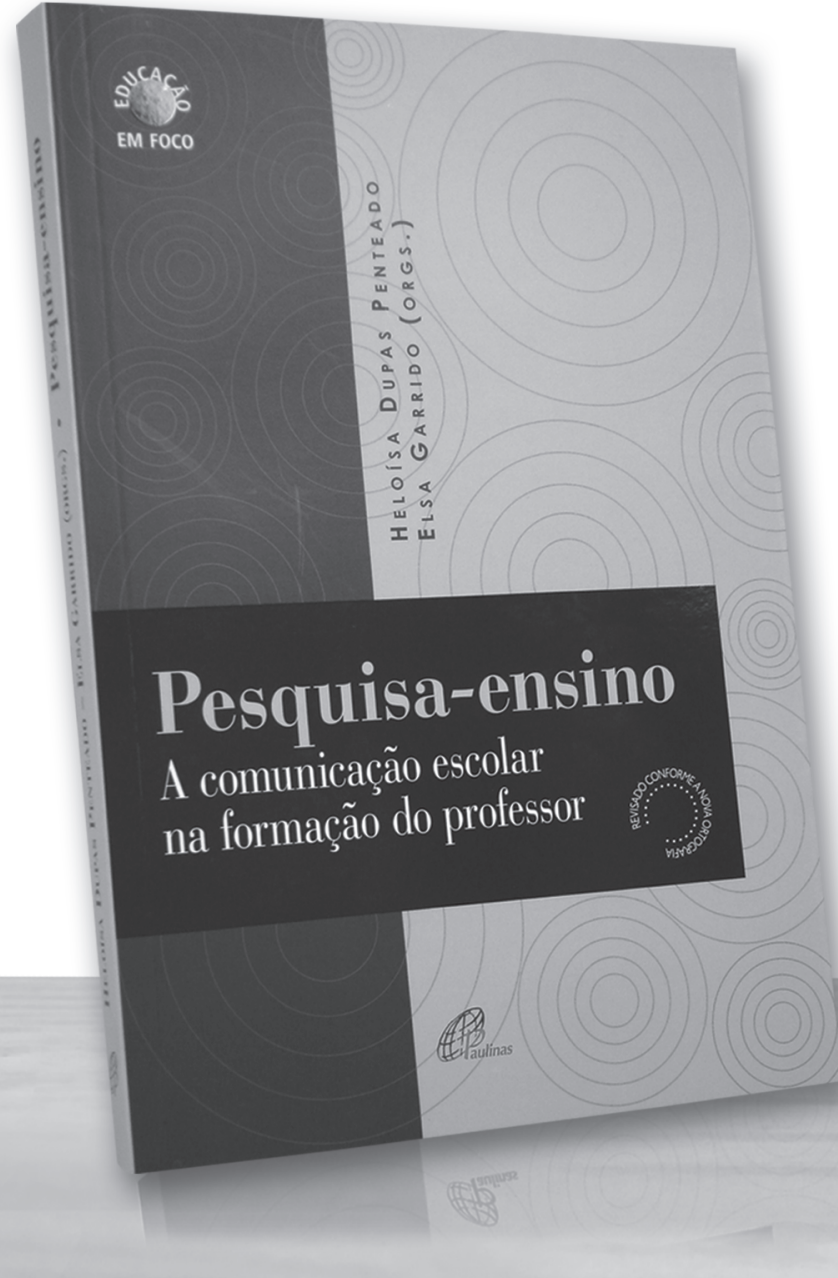
co) discute o valor da pesquisa-ensino, capaz de fazer da escola espaço de comunicação e cidadania. Defende que a cultura midiática, inserida nos processos de ensino-aprendizagem, se volte para a qualificação e formação do indivíduo, afinal, enquanto processo comunicacional, a educação escolar, mesmo sem suporte, inevitavelmente, entra em contato com essas mídias tecnológicas.

Na verdade, os artigos são um convite aos professores para que superem o isolamento e se associem a grupos de estudo e pesquisa "com o intuito de pensar suas práticas, partilhar questionamentos e experiências, analisar e compreender as relações dos alunos com o conhecimento e as dificuldades que esse lhes apresentam, para transformar sua atividade profissional em atividade de pesquisa reflexiva e criadora".

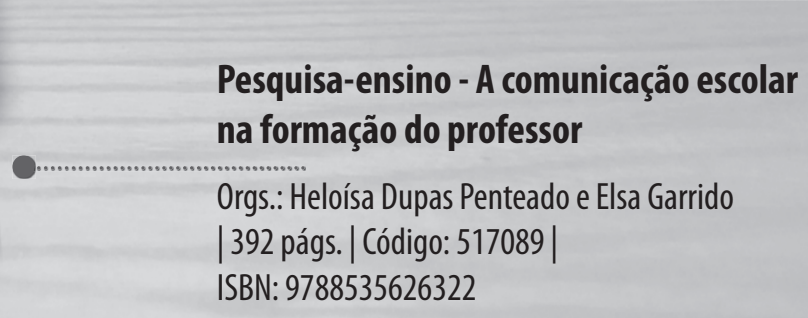

À venda na Rede Paulinas de Livrarias Se preferir, ligue 08007010081 ou acesse www.paulinas.org.br/loja 